\title{
The effect of sevoflurane versus desflurane on postoperative catheter-related bladder discomfort in patients undergoing transurethral excision of a bladder tumour: a randomized controlled trial
}

\section{Effet du sévoflurane comparé au desflurane sur l'inconfort lié à la sonde vésicale en période postopératoire chez les patients subissant l'excision transurétrale d'une tumeur à la vessie: une étude randomisée contrôlée}

\author{
Hyun-Chang Kim, MD • Won-Pyo Hong, MD · Young-Jin Lim, MD • \\ Hee-Pyoung Park, MD \\ Received: 9 September 2015/Revised: 12 November 2015/Accepted: 25 January 2016/Published online: 1 February 2016 \\ (C) Canadian Anesthesiologists' Society 2016
}

\begin{abstract}
Purpose Catheter-related bladder discomfort (CRBD) due to an indwelling urinary catheter can cause postoperative distress, and the mechanism underlying $C R B D$ is linked to the activation of muscarinic receptors. Inhalation of anesthetic agents, such as sevoflurane and desflurane, has differential inhibitory effects on muscarinic receptors. We aimed to compare the effect of intraoperative sevoflurane vs desflurane inhalation on postoperative $C R B D$.
\end{abstract}

Methods Eighty-nine patients undergoing transurethral resection of a bladder tumour (TURBT) were randomly allocated to two groups. The sevoflurane group $(n=45)$ and the desflurane group $(n=44)$ received the respective inhalational agents for maintenance of general anesthesia. The incidence and severity (mild/moderate/severe) of CRBD were assessed at zero, one, six, and $24 \mathrm{hr}$ postoperatively.

Results Catheter-related bladder discomfort during the first 24 hr postoperatively occurred in 34/45 (76\%) patients

\section{H.-C. Kim, MD}

Department of Anesthesiology and Pain Medicine, Keimyung University Dongsan Hospital, Keimyung University College of Medicine, Daegu, Korea

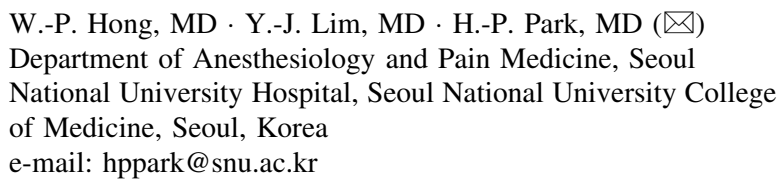

receiving sevoflurane compared with $41 / 44$ (93\%) patients receiving desflurane [absolute difference 18\%; $95 \%$ confidence interval [CI], 2 to 33; $P=0.039]$. The differences in the rate of $C R B D$ between the sevoflurane and desflurane groups at zero, one, and six hours postoperatively were $24 \%(95 \% C I, 7$ to $40 ; P=0.012)$, $33 \%$ (95\% CI, 15 to $49 ; P=0.001)$, and $26 \%(95 \%$ CI, 6 to 43; $P=0.019)$, respectively. The incidence of moderate to severe CRBD and the number of patients treated with tramadol for CRBD were comparable between the two groups.

Conclusions As a maintenance agent of general anesthesia, sevoflurane reduced the incidence of early postoperative CRBD in patients undergoing TURBT when compared with desflurane. The protocol for this clinical trial was registered at ClinicalTrials.gov (NCT02096224).

\section{Résumé}

Objectif Le syndrome d'inconfort lié à la sonde vésicale causé par une sonde urinaire à demeure peut entraîner de la détresse en période postopératoire; le mécanisme sous-jacent à ce syndrome est lié à l'activation des récepteurs muscariniques. L'inhalation d'agents anesthésiques tels que le sévoflurane et le desflurane a des effets inhibiteurs différentiels sur les récepteurs muscariniques. Notre objectif était de comparer l'effet d'une inhalation peropératoire de sévoflurane vs de desflurane sur l'inconfort lié à la sonde vésicale en période postopératoire.

Méthode Quatre-vingt-neuf patients subissant une résection transurétrale de tumeur de vessie (RTUTV) ont 
été aléatoirement répartis en deux groupes. Le groupe sévoflurane $(n=45)$ et le groupe desflurane $(n=44)$ ont reçu, respectivement, l'un ou l'autre de ces agents d'inhalation pour le maintien de l'anesthésie générale. L'incidence et la gravité (légère / modérée / grave) du syndrome d'inconfort ont été évaluées à zéro, une, six et 24 $h$ postopératoires.

Résultats Un syndrome d'inconfort lié à la sonde vésicale est survenu durant les premières $24 \mathrm{~h}$ postopératoires chez 34/45 (76\%) des patients recevant du sévoflurane par rapport à $41 / 44$ (93\%) des patients recevant du desflurane [différence absolue $18 \%$; intervalle de confiance [IC] $95 \%, 2$ à 33; $P=0$,039]. Les différences dans le taux de syndromes entre les groupes sévoflurane et desflurane à zéro, une et six heures postopératoires étaient de $24 \%$ (IC $95 \%, 7$ à 40; $P=0,012), 33 \%$ (IC $95 \%, 15$ à 49; $P=0,001)$, et $26 \%($ IC $95 \%, 6$ à 43; $P=0,019)$, respectivement. L'incidence de syndromes modérés à graves et le nombre de patients traités au tramadol pour un syndrome d'inconfort lié à la sonde vésicale étaient comparables dans les deux groupes.

Conclusion En tant qu'agent de maintien de l'anesthésie générale, le sévoflurane a réduit l'incidence d'inconfort postopératoire précoce lié à la sonde vésicale chez les patients subissant un RTUTV par rapport au desflurane. Le protocole de cette étude clinique a été enregistré au ClinicalTrials.gov (NCT02096224).

Catheter-related bladder discomfort (CRBD) is defined as a burning sensation with an urge to void or as discomfort in the suprapubic area caused by irritation of the bladder due to a urinary catheter. ${ }^{1}$ This uncomfortable symptom can increase postoperative distress and agitation. ${ }^{2-5}$ The mechanism of CRBD is similar to that of overactive bladder syndrome in which activation of muscarinic receptors, especially the type 3 muscarinic (M3) receptor, results in the frequent urge to void. ${ }^{6}$ A variety of agents with antimuscarinic properties, such as ketamine, tolterodine, tramadol, and butylscopolamine, have been investigated for their ability to prevent or treat CRBD. ${ }^{1,7-9}$ Although these agents reduced the incidence and severity of CRBD, they carried additional side effects, including nausea, vomiting, sedation, and dry mouth.

Sevoflurane and desflurane are frequently used for general anesthesia during bladder surgery and they have differential effects on muscarinic acetylcholine receptors, especially the M3 receptor. ${ }^{10,11}$ Sevoflurane shows dosedependent inhibition of the muscarinic receptor. This inhibitory phenomenon is particularly evident at a sevoflurane concentration of about $\geq 1$ MAC. In contrast, desflurane has a biphasic effect (i.e., no effect or a stimulatory effect at about 1-2 MAC and an inhibitory effect at about 3.5 MAC). ${ }^{11}$ Nevertheless, there is a lack of studies investigating the effects of sevoflurane and desflurane on postoperative CRBD.

This investigation was designed to compare the effect of intraoperative sevoflurane $v s$ desflurane inhalation on the overall incidence of CRBD within the first postoperative 24 $\mathrm{hr}$ in patients undergoing transurethral resection of a bladder tumour (TURBT). We hypothesized that sevoflurane could reduce the incidence of CRBD to a greater extent than desflurane.

\section{Methods}

The Institutional Review Board of Seoul National University Hospital approved this prospective randomized investigation on April 29, 2014 (document number: H1403-071-564). Patients aged 18-80 yr with American Society of Anesthesiologists physical status I-III and scheduled for elective TURBT were recruited from MayJuly 2014. Exclusion criteria were bladder outflow obstruction, overactive bladder (frequency greater than three times per night or more than eight times per $24 \mathrm{hr}$ ), end-stage renal disease (serum creatinine $>1.6 \mathrm{mg} \cdot \mathrm{dL}^{-1}$ ), neurogenic bladder, heart failure, arrhythmia, morbid obesity, use of chronic analgesic medication, current medication with anticholinergic effect (e.g., dimenhydrinate and tricyclic antidepressant), and hepatic, pulmonary, or psychiatric disease.

An anesthesia resident not involved in the data collection obtained written informed consent from eligible patients. Patients were educated about the symptoms of CRBD, which is characterized as a burning sensation with an urge to void or as discomfort in the suprapubic area. One anesthesia nurse blinded to the study protocol randomly assigned participants to either the sevoflurane or the desflurane group. The randomization was sequenced into blocks of four and six with the help of Random Allocation Software, version 1.0.0 (Isfahan University of Medical Sciences, Isfahan, Iran). The assignments were concealed in opaque envelopes and opened immediately before induction.

General anesthesia with muscle relaxation was applied to prevent any movement of lower extremities, especially adduction of the thigh, during TURBT. Anesthesia was induced with propofol $2 \mathrm{mg} \cdot \mathrm{kg}^{-1}$ and a target-controlled continuous infusion of remifentanil $2 \mathrm{ng} \cdot \mathrm{mL}^{-1}$. After administering rocuronium $0.6 \mathrm{mg} \cdot \mathrm{kg}^{-1}$, an i-gel ${ }^{\circledR}$ supraglottic airway device (Intersurgical Ltd., Berkshire, UK) was inserted. Sevoflurane and desflurane were used to maintain anesthesia in their respective groups. The targetcontrolled continuous infusion of remifentanil was carried 
out in both groups using the Orchestra ${ }^{\circledR}$ Base Primea modular infusion station (Fresenius Kabi, Brezins, France). The concentration of inhalational agents and remifentanil were adjusted to maintain a bispectral index of 40-60 and a systolic blood pressure within $\pm 20 \%$ of baseline. The bladder tumour was resected cystoscopically using a Ushaped electrocautery device. At the end of the procedure, a large ( $\geq 20$ Fr) Foley urinary catheter was inserted and fixed to the patient's leg without any traction using adhesive tape. The bladder was irrigated continuously with normal saline through the urinary catheter. The Foley catheter was removed $24 \mathrm{hr}$ postoperatively. Atropine 15 $\mu \mathrm{g} \cdot \mathrm{kg}^{-1}$ mixed with neostigmine $25 \mu \mathrm{g} \cdot \mathrm{kg}^{-1}$ was administered for the reversal of muscle relaxation. Average sevoflurane and desflurane concentrations during surgery were recorded and presented as mean age-adjusted MAC to compare the gas concentration of both inhalational anesthetics used intraoperatively. Age-adjusted MAC was calculated using Mapleson's method in both groups $\left(\mathrm{MAC}_{\mathrm{age}}=\mathrm{MAC}_{40} * 10^{[-0.00269 *(\text { age }-40)]}, \quad \mathrm{MAC}_{40}\right.$ : MAC value at $40 \mathrm{yr}$ old). ${ }^{12}$

If patients complained of a symptom and sign of CRBD, the severity of CRBD was evaluated as one of three grades: "mild" when reported by patients only on questioning, "moderate" when reported to a physician or a nurse by patients on their own (without questioning and not accompanied by any behavioural response), and "severe" when reported by patients on their own along with behavioural responses (flailing limbs, strong vocal response, and attempt to pull out the catheter). ${ }^{1,2,7,8} \mathrm{An}$ anesthesiology resident or nurse blinded to the group assignments assessed the incidence and severity of CRBD at zero, one, six, and $24 \mathrm{hr}$ postoperatively. When moderate or severe CRBD was reported, tramadol at $50-100 \mathrm{mg}$ was intravenously administered as a rescue therapy. Postoperative surgical pain, defined as sharp, stinging, and tingling pain at the suprapubic region, was recorded using an 11-point numerical rating scale $(0=$ no pain to $10=$ worst pain imaginable) at zero, one, six, and $24 \mathrm{hr}$ postoperatively. When the postoperative pain score was $\geq 4$ on the numerical rating scale, fentanyl $50 \mu \mathrm{g}$ or Demerol $25 \mathrm{mg}$ was administered for pain relief. The presence of postoperative nausea, vomiting, and dry mouth was also recorded.

The primary endpoint measure was the overall incidence of CRBD in the first 24 postoperative hours. The secondary endpoint measures were the incidence and severity of CRBD at each time point and the number of patients treated with tramadol for CRBD.

\section{Statistical analysis}

Based on our previous study, ${ }^{13} 90 \%$ of patients complained of CRBD within the first $24 \mathrm{hr}$ following TURBT when desflurane was used for maintenance of general anesthesia. We calculated that 35 patients would be necessary in each group to acquire statistical significance with $\alpha=0.05$ and $\beta$ $=0.20$. This calculation presumes a $30 \%$ reduction in the overall rate of CRBD within the first postoperative $24 \mathrm{hr}$ in the sevoflurane group, which is considered clinically significant. Considering a $20 \%$ dropout rate, we included 46 patients in each group. We used IBM SPSS ${ }^{\circledR}$ Statistics version 19.0 (Armonk, NY, USA) for the statistical analysis. The incidences of CRBD, postoperative nausea and vomiting, dry mouth, and the number of patients treated with tramadol or opioids were compared between groups using the Chi square test or Fisher's exact test (if observed value per cell $\leq 5$ ). The severity of CRBD was compared between groups using the cross-tabulation analysis with the Chi square test, and the intraoperative concentration of the two inhalation agents was compared between groups using Student's $t$ test. The postoperative pain score was analyzed by repeated-measures analysis of variance for time by treatment interaction, and the Student's $t$ test was then used to compare values between groups at each time point. The alpha value adjustment with Bonferroni's correction (i.e., the alpha value divided by the number of comparisons) was performed to compare the incidence and severity of CRBS and postoperative pain scores between the two groups at each time point. In other words, because there were four comparisons, the alpha values were adjusted to 0.0125 and 0.0025 instead of 0.05 and 0.01 , respectively. The $P$ values were compared with these adjusted alpha values. Otherwise, all reported $P$ values are two sided.

\section{Results}

During the enrolment process, 108 patients were approached to participate in the study. Nineteen patients were excluded because they met the exclusion criteria $(n=$ $14)$, refused to participate $(n=2)$, or surgery was cancelled $(n=3)$, leaving 89 patients for analysis (Figure). Patient characteristics in the two groups were similar (Table 1). The equivalent MAC depth was maintained in both groups (the average age-adjusted MAC was 0.7 for both sevoflurane and desflurane).

Catheter-related bladder discomfort during the first $24 \mathrm{hr}$ postoperatively occurred in 34/45 (76\%) patients receiving sevoflurane compared with 41/44 (93\%) patients receiving desflurane [absolute difference 18\%; 95\% confidence interval $[\mathrm{CI}], 2$ to $33 ; P=0.039]$. At zero, one, and six hours postoperatively, the difference in the rate of CRBD between groups was $24 \%$ (95\% CI, 7 to $40 ; P=0.012$ ), $33 \%$ (95\% CI, 15 to $49 ; P=0.001$ ), and $26 \%$ (95\% CI, 6 to $43 ; P=0.019)$, respectively. The incidence of moderate to 
Figure A CONSORT diagram showing the flow of participants through the phases of the trial

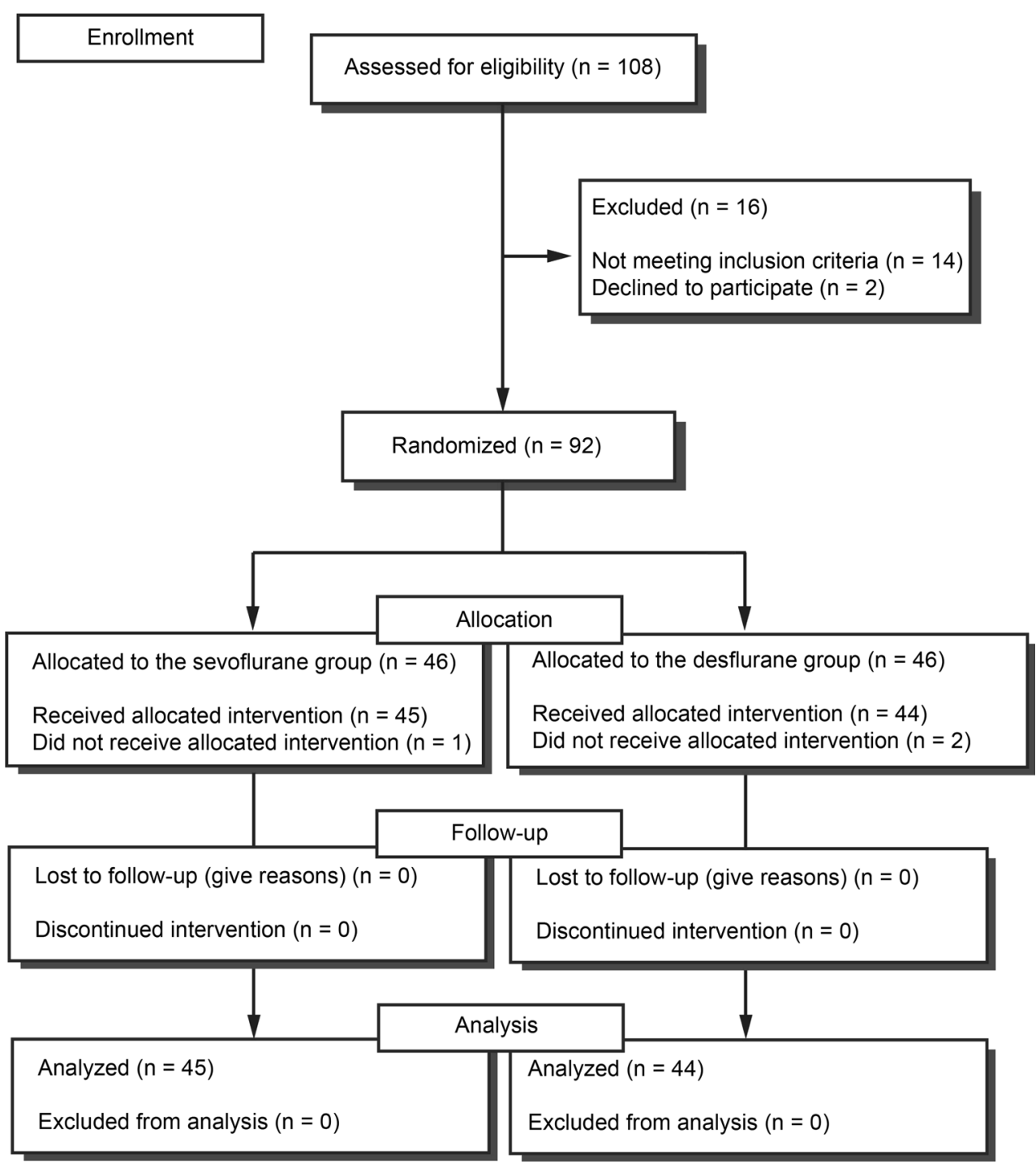

severe CRBD was not significantly different between the sevoflurane and desflurane groups at zero [10/45 (22\%) vs $16 / 44$ (36\%), respectively; $P=0.217$ ], one [5/45 (11\%) vs $11 / 44(25 \%)$, respectively; $P=0.104]$, and six hours $[1 / 45$ $(2 \%)$ vs $1 / 44$ (2\%), respectively; $P=1.000]$ postoperatively. The number of patients given tramadol for CRBD treatment did not differ between the sevoflurane and desflurane groups [15/45 (33\%) vs 21/44 (48\%), respectively; $P=0.243$ ].

The mean (SD) postoperative pain scores were not significantly different between the sevoflurane and

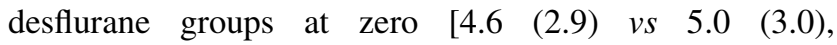
respectively; $P=0.575]$, one $[3.4$ (2.5) vs 4.6 (2.7), respectively; $P=0.028]$, six $[2.3$ (1.9) vs 3.0 (2.3), respectively; $P=0.148$ ], and $24 \mathrm{hr}[1.2$ (1.5) vs 1.3 (1.3), respectively; $P=0.811$ ] (Table 2 ). Twelve patients in the sevoflurane group and 18 patients in the desflurane group were treated with either fentanyl or Demerol for postoperative pain $(P=0.231)$.

No significant differences were observed in the incidence of postoperative nausea between the sevoflurane and desflurane groups $[0$ (0\%) vs $3(7 \%)$, respectively; $P=0.117$ ], and no patient in either group vomited postoperatively. The incidence of dry mouth was comparable between the two groups [4 (9\%) vs 2 (5\%), $P=$ $0.677]$.

\section{Discussion}

This study shows that sevoflurane was associated with less frequent postoperative CRBD than desflurane in patients undergoing TURBT. The beneficial effect of sevoflurane lasted for one hour postoperatively. 
Table 1 Baseline characteristics of patients

\begin{tabular}{|c|c|c|}
\hline & $\begin{array}{l}\text { Sevoflurane } \\
(n=45)\end{array}$ & $\begin{array}{l}\text { Desflurane } \\
(n=44)\end{array}$ \\
\hline Age (yr) & $65.6(10.7)$ & $66.6(7.6)$ \\
\hline Male & $35(78 \%)$ & $38(86 \%)$ \\
\hline Weight (kg) & $66.6(10.3)$ & $65.7(8.7)$ \\
\hline Height $(\mathrm{cm})$ & $163(7)$ & $164(8)$ \\
\hline Body mass index $\left(\mathrm{kg} \cdot \mathrm{m}^{-2}\right)$ & $24.9(2.8)$ & $24.3(2.5)$ \\
\hline Previous TURBT history & $25(56 \%)$ & $23(52 \%)$ \\
\hline Duration of surgery (min) & $21.6(10.8)$ & $23.9(15.2)$ \\
\hline Time to extubation (min) & $8.5(3.8)$ & $8.3(4.2)$ \\
\hline $\begin{array}{l}\text { Inhalation concentration } \\
\text { (age-adjusted MAC) }\end{array}$ & $0.7(0.2)$ & $0.7(0.1)$ \\
\hline Intraoperative remifentanil $(\mu \mathrm{g})$ & $158.3(62.0)$ & $150.1(63.0)$ \\
\hline \multicolumn{3}{|l|}{ Maximum tumour size } \\
\hline$<1 \mathrm{~cm}$ & $30(66.7 \%)$ & $29(65.9 \%)$ \\
\hline$>1 \mathrm{~cm}$ & $15(33.3 \%)$ & $15(34.1 \%)$ \\
\hline \multicolumn{3}{|l|}{ Tumour number } \\
\hline$<5$ & $30(66.7 \%)$ & $32(72.7 \%)$ \\
\hline$>5$ & $15(33.3 \%)$ & $12(27.3 \%)$ \\
\hline \multicolumn{3}{|l|}{ Resection depth } \\
\hline Mucosa & $2(4.4 \%)$ & $0(0.0 \%)$ \\
\hline Submucosa & $2(4.4 \%)$ & $4(9.1 \%)$ \\
\hline Muscle & $41(91.1 \%)$ & $40(90.9 \%)$ \\
\hline \multicolumn{3}{|l|}{ Urinary catheter size } \\
\hline $20 \mathrm{Fr}$ & $42(93 \%)$ & $43(98 \%)$ \\
\hline $22 \mathrm{Fr}$ & $2(5 \%)$ & $1(2 \%)$ \\
\hline $24 \mathrm{Fr}$ & $1(2 \%)$ & $0(0 \%)$ \\
\hline
\end{tabular}

Values are presented as mean (SD) or number of patients (\%). MAC $=$ minimum alveolar concentration; TURBT $=$ transurethral resection of bladder tumour

Patients with intraoperative urinary catheterization under general anesthesia often complain of CRBD in the postanesthesia care unit. Nevertheless, CRBD is usually neglected and left untreated. Catheter-related bladder discomfort has been identified as a risk factor for the occurrence of emergence agitation during anesthetic recovery, especially in the postanesthesia care unit. ${ }^{14}$ Therefore, the use of anesthetic agents that reduce the incidence of CRBD can be helpful in decreasing this agitation.

Catheter-related bladder discomfort may be unresponsive to common pain management modalities because of the different pathologic mechanism. The muscarinic receptors, especially type 3 and 2, are commonly involved in the pathologic mechanism of bladder contractility disorders such as overactive bladder syndrome and CRBD. ${ }^{15-17}$ The M3 receptor is related to direct contraction of the bladder, while the $\mathrm{M} 2$ receptor is associated with indirect contraction of the bladder by either enhancing the effect of $\mathrm{M} 3$ or by reversing the relaxation caused by a cyclic adenosine monophosphate (cAMP)induced beta-adrenergic effect. ${ }^{17}$

In previous studies, various agents with antimuscarinic properties, such as gabapentin, oxybutynin, tolterodine, and tramadol, were found to reduce the incidence and severity of postoperative CRBD. ${ }^{1,2,7-9,18-20}$ In this study, use of sevoflurane resulted in a greater reduction in the incidence of CRBD when compared with desflurane by $24 \%, 33 \%$, and $26 \%$ at zero, one, and six hours after surgery, respectively. This preventive effect of sevoflurane on CRBD is similar to that of antimuscarinic agents reported in previous studies in which tolterodine and gabapentin reduced the incidence of CRBD by $19-30 \%$ until six hours postoperatively. ${ }^{1,18}$

The use of antimuscarinic agents for the treatment of CRBD increased the incidence of postoperative side effects, including dry mouth, nausea, vomiting, and sedation. ${ }^{1,7,8,18,19}$ For example, the use of antimuscarinic agents tolterodine and oxybutynin increased the incidence of dry mouth (59\%), while the use of tramadol increased the incidences of sedation (92\%), nausea $(56 \%)$, and vomiting (40\%). ${ }^{1,8,19}$ In this study, the incidences of dry mouth, nausea, and vomiting were within $10 \%$ in both the sevoflurane and desflurane groups during the entire study period. This finding suggests that sevoflurane and desflurane inhalation, regardless of the chosen inhalation agent, showed fewer antimuscarinic side effects compared with antimuscarinic agents used for CRBD treatment in previous studies. ${ }^{1,8,19}$

In our investigation, the overall incidence of CRBD was $41 / 44$ (93\%) patients in the desflurane group. The incidence of CRBD has been reported to be $58-71 \%$. $^{8,9,19}$ The relatively high incidence of CRBD in this study is related to TURBT. In patients undergoing TURBT, the bladder mucosa is electrically cauterized and a large Foley catheter is introduced postoperatively. Male sex and the diameter of the Foley catheter are known risk factors for CRBD ${ }^{21}$ Moreover, continuous irrigation of the bladder to prevent urinary tract obstruction by blood clots and reimplantation of cancer cells often irritates the bladder wall. Because of these predisposing factors, patients undergoing TURBT are at high risk of CRBD, which explains the relatively high incidence of CRBD in our investigation. Indeed, in a previous report, $90 \%$ of patients undergoing TURBT complained of postoperative CRBD. ${ }^{20}$

Several limitations of the current study should be considered. First, although the ability of sevoflurane and desflurane to prevent CRBD was investigated, we did not evaluate the extent of M3 receptor inhibition by both agents. Furthermore, we did not evaluate the combined effect of the inhalational agent with other antimuscarinic agents in this study because we did not routinely administer the antimuscarinic agent for the prevention of CRBD. 
Table 2 Incidence and severity of postoperative catheter-related bladder discomfort and postoperative pain score

\begin{tabular}{|c|c|c|c|c|}
\hline & $\begin{array}{l}\text { Sevoflurane } \\
(n=45)\end{array}$ & $\begin{array}{l}\text { Desflurane } \\
(n=44)\end{array}$ & $\begin{array}{l}\text { Difference } \\
(95 \% \text { CI })\end{array}$ & $P$ value \\
\hline \multicolumn{5}{|l|}{ CRBD } \\
\hline Overall incidence & $34(76 \%)$ & $41(93 \%)$ & $18 \%$ (2 to 33$)$ & 0.039 \\
\hline \multicolumn{5}{|l|}{ Postoperative $0 \mathrm{hr}$} \\
\hline Incidence & $29(64 \%)$ & $39(89 \%)$ & $24 \%$ (7 to 40$)$ & 0.012 \\
\hline \multicolumn{5}{|l|}{ Severity } \\
\hline Mild & $19(42 \%)$ & $23(52 \%)$ & $10 \%(-10$ to 29$)$ & 0.461 \\
\hline Moderate & $10(22 \%)$ & $16(36 \%)$ & $14 \%(-5$ to 32$)$ & 0.217 \\
\hline \multicolumn{5}{|l|}{ Postoperative $1 \mathrm{hr}$} \\
\hline Incidence & $25(56 \%)$ & $39(89 \%)$ & $33 \%$ (15 to 49 ) & 0.001 \\
\hline \multicolumn{5}{|l|}{ Severity } \\
\hline Mild & $20(44 \%)$ & $28(64 \%)$ & $19 \%(-1$ to 38$)$ & 0.109 \\
\hline Moderate & $5(11 \%)$ & $11(25 \%)$ & $14 \%(-2$ to 30$)$ & 0.104 \\
\hline \multicolumn{5}{|l|}{ Postoperative $6 \mathrm{hr}$} \\
\hline Incidence & $23(51 \%)$ & $34(77 \%)$ & $26 \%$ (6 to 43$)$ & 0.019 \\
\hline \multicolumn{5}{|l|}{ Severity } \\
\hline Mild & $22(49 \%)$ & $33(75 \%)$ & $26 \%(6$ to 44$)$ & 0.021 \\
\hline Moderate & $1(2 \%)$ & $1(2 \%)$ & $0 \%$ ( -9 to 10$)$ & 1.000 \\
\hline \multicolumn{5}{|l|}{ Postoperative $24 \mathrm{hr}$} \\
\hline Incidence & $12(27 \%)$ & $14(32 \%)$ & $5 \%(-13.5$ to 23$)$ & 0.763 \\
\hline \multicolumn{5}{|l|}{ Severity } \\
\hline Mild & $12(27 \%)$ & $14(32 \%)$ & $5 \%(-13.5$ to 23$)$ & 0.763 \\
\hline Moderate & $0(0 \%)$ & $0(0 \%)$ & NA & NA \\
\hline Number of patients receiving tramadol administration & $15(33 \%)$ & $21(48 \%)$ & $14 \%(-6$ to 33$)$ & 0.243 \\
\hline \multicolumn{5}{|l|}{ Pain score } \\
\hline Postoperative $0 \mathrm{hr}$ & $4.6(2.9)$ & $5.0(3.0)$ & $0.4(-0.9$ to 1.6$)$ & 0.575 \\
\hline Postoperative $1 \mathrm{hr}$ & $3.4(2.5)$ & $4.6(2.7)$ & $1.2(0.1$ to 2.3$)$ & 0.028 \\
\hline Postoperative $6 \mathrm{hr}$ & $2.3(1.9)$ & $3.0(2.3)$ & $0.6(-0.2$ to 1.5$)$ & 0.148 \\
\hline Postoperative $24 \mathrm{hr}$ & $1.2(1.5)$ & $1.3(1.3)$ & $0.1(-0.5$ to 0.7$)$ & 0.811 \\
\hline
\end{tabular}

Values are presented as mean (SD) or number of patients (\%). CI = confidence interval; CRBD = catheter-related bladder discomfort; NA = Not applicable

Second, TURBT per se can cause mild suprapubic pain, and such postoperative surgical pain may be misinterpreted as a symptom of CRBD due to the difficulty in differentiating symptoms of CRBD from postoperative surgical pain. Moreover, opioids used to control postoperative pain can mask symptoms of CRBD, although there is a lack of studies reporting that opioids are effective in relieving postoperative CRBD. In this study, however, patients were preoperatively educated about the symptoms of CRBD to distinguish it from postoperative surgical pain at the suprapubic area. In our view, the symptoms of CRBD (defined as a burning sensation with urgent urination and discomfort at the suprapubic area with mild and dull characteristics) is different from postoperative sharp, stinging, and tingling pain at the suprapubic region due to electrocauterization during TURBT. Third, the intrinsic analgesic effect of inhalational agents may affect the incidence and severity of CRBD. Specifically, inhalational agents decrease postoperative surgical pain and obtund uncomfortable sensory input originating from contractions of the bladder muscles caused by activation of muscarinic receptors-sevoflurane provides effective analgesia for visceral pain. ${ }^{22-24}$ Fourth, there is a limitation in generalizing our results because various patient populations with different CRBD triggers were not included in this study. In other words, CRBD can be triggered by various factors, including foreign bodies in the bladder, cauterization of the bladder mucosa, intravesical chemotherapy, and bladder sutures. The incidence, severity, and duration of CRBD may be different in patients undergoing surgery unrelated to the lower urinary tract (e.g., nephrectomy), open/laparoscopic bladder surgery with bladder sutures (e.g., partial cystectomy), or 
in patients exposed to locally irritating bladder instillations after bladder surgery. Finally, we could not blind the attending anesthetists controlling the depth of the anesthesia. To reduce the bias, a physician or nurse blinded to the group assignments performed the outcome measurements and postoperative management.

In conclusion, use of sevoflurane resulted in a greater reduction in the incidence of early postoperative CRBD compared with desflurane without serious side effects in patients undergoing TURBT. Therefore, we recommend the use of sevoflurane as a maintenance agent for general anesthesia in patients at high risk of CRBD.

Author contributions: Hyun-Chang Kim, Won-Pyo Hong, Young-Jin Lim, and Hee-Pyoung Park designed the study and collected the data. Hyun-Chang Kim and Hee-Pyoung Park analyzed the data and wrote the manuscript.

Acknowledgement We sincerely thank Dr. Younsuk Lee (Dongguk University) for his valuable statistical advice.

Funding None.

Conflicts of interest None to declare.

\section{References}

1. Agarwal A, Raza M, Singhal V, et al. The efficacy of tolterodine for prevention of catheter-related bladder discomfort: a prospective, randomized, placebo-controlled, double-blind study. Anesth Analg 2005; 101: 1065-7.

2. Tauzin-Fin P, Sesay M, Svartz L, Krol-Houdek MC, Maurette P. Sublingual oxybutynin reduces postoperative pain related to indwelling bladder catheter after radical retropubic prostatectomy. Br J Anaesth 2007; 99: 572-5.

3. Guenther U, Radtke FM. Delirium in the postanaesthesia period. Curr Opin Anaesthesiol 2011; 24: 670-5.

4. Lepouse C, Lautner CA, Liu L, Gomis P, Leon A. Emergence delirium in adults in the post-anaesthesia care unit. $\mathrm{Br} \mathrm{J}$ Anaesth 2006; 96: 747-53.

5. Kim HC, Kim E, Jeon YT, et al. Postanaesthetic emergence agitation in adult patients after general anaesthesia for urological surgery. J Int Med Res 2015; 43: 226-35.

6. Anderson KE. Pharmacology of lower urinary tract smooth muscles and penile erectile tissues. Pharmacol Rev 1993; 45: 253-308.

7. Agarwal A, Gupta D, Kumar M, Dhiraaj S, Tandon M, Singh PK. Ketamine for treatment of catheter related bladder discomfort: a prospective, randomized, placebo controlled and double-blind study. Br J Anaesth 2006; 96: 587-9.

8. Agarwal A, Yadav G, Gupta D, Singh PK, Singh U. Evaluation of intra-operative tramadol for prevention of catheter-related bladder discomfort: a prospective, randomized, double-blind study. Br J Anaesth 2008; 101: 506-10.

9. Ryu JH, Hwang JW, Lee JW, et al. Efficacy of butylscopolamine for the treatment of catheter-related bladder discomfort: a prospective, randomized, placebo-controlled, double-blind study. Br J Anaesth 2013; 111: 932-7.

10. Nakayama T, Penheiter AR, Penheiter SG, et al. Differential effects of volatile anesthetics on M3 muscarinic receptor coupling to the Galphaq heterotrimeric $G$ protein. Anesthesiology 2006; 105: 313-24.

11. Nietgen GW, Honemann $C W$, Chan $C K$, Kamatchi GL, Durieux $M E$. Volatile anaesthetics have differential effects on recombinant $\mathrm{m} 1$ and $\mathrm{m} 3$ muscarinic acetylcholine receptor function. Br J Anaesth 1998; 81: 569-77.

12. Mapleson $W W$. Effect of age on MAC in humans: a metaanalysis. Br J Anaesth 1996; 76: 179-85.

13. Kim HC, Lee YH, Jeon YT, et al. The effect of intraoperative dexmedetomidine on postoperative catheter-related bladder discomfort in patients undergoing transurethral bladder tumour resection: a double-blind, randomised study. Eur J Anaesthesiol 2015; 32: 596-601.

14. Yu D, Chai $W$, Sun $X$, Yao L. Emergence agitation in adults: risk factors in 2,000 patients. Can J Anesth 2010; 57: 843-8.

15. Appell RA. Clinical efficacy and safety of tolterodine in the treatment of overactive bladder: a pooled analysis. Urology 1997; 50(6A Suppl): 90-6.

16. Eglen RM. Muscarinic receptor subtypes in neuronal and nonneuronal cholinergic function. Auton Autacoid Pharmacol 2006; 26: 219-33.

17. Chess-Williams $R$. Muscarinic receptors of the urinary bladder: detrusor, urothelial and prejunctional. Auton Autacoid Pharmacol 2002; 22: 133-45.

18. Agarwal A, Dhiraaj S, Pawar S, Kapoor R, Gupta D, Singh PK. An evaluation of the efficacy of gabapentin for prevention of catheter-related bladder discomfort: a prospective, randomized, placebo-controlled, double-blind study. Anesth Analg 2007; 105: 1454-7.

19. Agarwal A, Dhiraaj S, Singhal V, Kapoor $R$, Tandon $M$. Comparison of efficacy of oxybutynin and tolterodine for prevention of catheter related bladder discomfort: a prospective, randomized, placebo-controlled, double-blind study. Br J Anaesth 2006; 96: 377-80.

20. Bala I, Bharti N, Chaubey VK, Mandal AK. Efficacy of gabapentin for prevention of postoperative catheter-related bladder discomfort in patients undergoing transurethral resection of bladder tumor. Urology 2012; 79: 853-7.

21. Binhas M, Motamed C, Hawajri N, Yiou R, Marty J. Predictors of catheter-related bladder discomfort in the post-anaesthesia care unit. Ann Fr Anesth Reanim 2011; 30: 122-5.

22. Duarte R, McNeill A, Drummond G, Tiplady B. Comparison of the sedative, cognitive, and analgesic effects of nitrous oxide, sevoflurane, and ethanol. Br J Anaesth 2008; 100: 203-10.

23. Larsen B, Seitz A, Larsen R. Recovery of cognitive function after remifentanil-propofol anesthesia: a comparison with desflurane and sevoflurane anesthesia. Anesth Analg 2000; 90: 168-74.

24. Yeo ST, Holdcroft A, Yentis SM, Stewart A. Analgesia with sevoflurane during labour: i. Determination of the optimum concentration. Br J Anaesth 2007; 98: 105-9. 